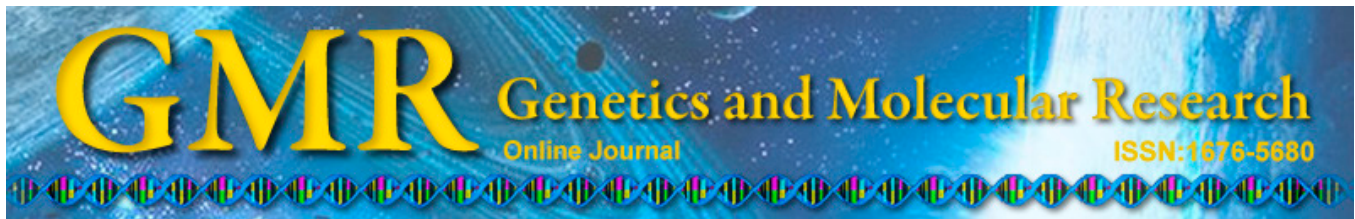

\title{
Effect of single nucleotide polymorphisms in the ATP-binding cassette B1 gene on the clini- cal outcome of traumatic brain injury
}

\author{
Z.L. Wang, D.S. Xu, Y.X. Wang, H. Qin and D. Geng \\ Department of Neurosurgery, \\ First Affiliated Hospital of Xinjiang Medical University, Urumqi, China \\ Corresponding author: Y.X. Wang \\ E-mail: wangyx_king@163.com
}

Genet. Mol. Res. 14 (3): 10948-10953 (2015)

Received January 12, 2015

Accepted May 15, 2015

Published September 21, 2015

DOI http://dx.doi.org/10.4238/2015.September.21.6

\begin{abstract}
The critical role of ATP-binding cassette B1 (ABCB1) in the function of the blood-brain barrier led us to conducted this prospective study in order to investigate the clinical outcome of patients suffering from severe traumatic brain injury. A total of 182 patients with traumatic brain injury were included in our study. Genotyping of $A B C B 1 \mathrm{C} 3435 \mathrm{~T}$ and $\mathrm{G} 2677 \mathrm{~T} / \mathrm{A}$ was conducted using polymerase chain reaction-restriction fragment length polymorphism. Using multivariatelogistic regression analysis, we found that patients carrying the $\mathrm{CT}+\mathrm{CC}$ genotype of $A B C B 1 \mathrm{C} 3435 \mathrm{~T}$ were more likely to have a better neurological outcome when compared with the TT genotype (odds ratio $=2.71,95 \%$ confidence interval $=1.12-6.86)$. However, no significant association was found between the G2677T/A polymorphism and outcome of traumatic brain injury patients. Our study provides important information regarding the prognostic value of $A B C B 1 \mathrm{C} 3435 \mathrm{~T}$, and the $A B C B 1 \mathrm{C} 3435 \mathrm{~T}$ polymorphism may be used as a predictive marker for the outcome of traumatic brain injury patients.
\end{abstract}

Key words: ATP-binding cassette B1 gene; Traumatic brain injury; Clinical outcome 


\section{INTRODUCTION}

Traumatic brain injury (TBI) is a serious disease and a leading cause of death and disability. An estimated 50,000 TBI-related deaths occurred in the United States in 2006 (Langlois et al., 2006). Primary injury is not the main cause of TBI, and traumatic space-occupying lesions and cerebral edema combined with raised intracranial pressure are the main causes of hypoxic ischemic damage. These subsequent complications typically cause herniation of brain tissue, inadequate cerebral perfusion, ischemia, or death (Miller et al., 1977; Padayachy et al., 2010). Numerous factors play important roles in the clinical outcome of TBI, including primary injury and treatment. Patients with TBI often show different clinical outcomes, even with similar pre-hospital treatment and demographics, suggesting that genetic factors play an important role in the clinical outcome of TBI. Previous studies showed that genetic factors, such as interleukin factors, kidney and brain-expressed protein, neurofilament, heavy polypeptide, endothelial nitric oxide synthase 3 , and poly(ADP-ribose) polymerase-1, can modify the pathophysiology and clinical outcome following TBI (Davidson et al., 2015).

ATP-binding cassette transporters, namely ABC proteins, are the main transport superfamilies and are responsible for regulating drug substrate absorption, distribution, and excretion (Leslie et al., 2005) across the blood-brain barrier (Hartz and Bauer, 2011). Previous studies have shown that ATP-binding cassette transporters can increase the active efflux of therapeutic substances in many central nervous system diseases, including nervous system neoplasms, psychiatric disorders, and epilepsy (Löscher and Potschka, 2005; Cotte et al., 2009). P-glycoprotein is encoded by the ATP-binding cassette $\mathrm{B} 1$ ( $A B C B 1)$ gene and is an efflux transporter located on the luminal side of intestinal epithelial cells (Hoffmeyer et al., 2000). $A B C B 1 \mathrm{C} 3435 \mathrm{~T}$ and $\mathrm{G} 2677 \mathrm{~T} / \mathrm{A}$ are the most frequently observed gene polymorphisms in the $A B C B 1$ gene and have been correlated with altered P-glycoprotein and lowered intestinal P-glycoprotein expression (Kim et al., 2001; Samanian et al., 2011). Several studies showed that $A B C B 1$ polymorphisms are associated with increased protein expression and antiepileptic drug resistance in Caucasian and Egyptian populations (Siddiqui et al., 2003; Ebid et al., 2007; Basic et al., 2008).

No studies have reported the role of $A B C B 1$ gene polymorphisms on the clinical outcome of TBI. Because of the critical role of ABCB1 in the functional blood-brain barrier, we conducted a prospective study to investigate the clinical outcomes of patients suffering from severe TBI.

\section{MATERIAL AND METHODS}

\section{Patient recruitment and data collection}

This prospective study was performed in the First Affiliated Hospital of Xinjiang Medical University between January 2010 and December 2011. A total of 182 patients with TBI were included in our study. Patients were included in the study if they had severe TBI and less than or equal to 8 as an initial value or deterioration in the Glasgow Coma Scale (GCS). Patients were excluded if they were diagnosed with a previous deficit in the central nervous system, penetrating TBI, and cardiac or respiratory arrest.

All patients signed informed consent for blood sample collection. The samples were used to establish the role of genetic polymorphisms in the prognosis of TBI. The study protocol was 
approved by the Ethics Committee of the First Affiliated Hospital of Xinjiang Medical University.

Demographic and clinical data were obtained from medical records and included gender, age, pattern of brain injury defined by computed tomography as focal mass lesion or diffuse injury, and initial clinical severity by GCS.

\section{Outcome measure}

All patients were followed up by direct interview in the clinic or by telephone every 4 weeks for 24 months. The primary outcome of TBI was assessed using the Glasgow Outcome Scale (GOS) score. During the follow-up period, the GOS scores were gained for all patients at 6 months. The Injury Severity Score (ISS) was assessed by trauma surgery doctors.

\section{Genotyping}

Each patient was asked to provide a sample of $5 \mathrm{~mL}$ venous blood, which was stored at $-20^{\circ} \mathrm{C}$. Genomic DNA was extracted from venous blood using the TIANamp blood DNA kit (Tiangen Biotech, Beijing, China) according to the manufacturer's instructions. Genotyping of $A B C B 1 \mathrm{C} 3435 \mathrm{~T}$ and $\mathrm{G} 2677 \mathrm{~T} / \mathrm{A}$ was conducted using polymerase chain reaction (PCR)-restriction fragment length polymorphism. Primers for $A B C B 1$ C3435T and G2677T/A were designed using the Sequenom Assay Design 3.1 software (Sequenom, San Diego, CA, USA). The PCR included the following steps: $94^{\circ} \mathrm{C}$ for $2 \mathrm{~min}, 35$ cycles at $94^{\circ} \mathrm{C}$ for $30 \mathrm{~s}$, with the annealing temperature reduced to $64^{\circ} \mathrm{C}$ for $30 \mathrm{~s}$, and $72^{\circ} \mathrm{C}$ for $1 \mathrm{~min}$. For $A B C B 1 \mathrm{C} 3435 \mathrm{~T}$, the PCR product was $244 \mathrm{bp}$ and digested with $\mathrm{MboI}$. For G2677T/A, the PCR product was $224 \mathrm{bp}$ and digested with BanI. Finally, DNA sequencing was performed to validate the genotyping results.

\section{Statistical analysis}

All analyses were performed using the SPSS 13.0 software for Windows (SPSS, Inc., Chicago, IL, USA). Correlation between the $A B C B 1$ C3435T and G2677T/A polymorphisms and the primary outcome of TBI (GOS at 6 months) was assessed using odds ratios and $95 \%$ confidence intervals from multivariate-logistic regression analysis. Homozygotes for the most frequent allele were regarded as the reference group. The clinical variables were statistically analyzed to assess their influence on the outcome of TBI patients. All P values were two-tailed, and differences were considered to be statistically significant when $\mathrm{P}<0.05$.

\section{RESULTS}

The demographic characteristics and gene frequencies of the patients included are shown in Table 1. The mean age of the TBI subjects was $34.8 \pm 11.6$ years. Of the 182 TBI patients, $123(67.58 \%)$ were males and $59(32.42 \%)$ were females. The mean initial GCS score was $5.8 \pm 1.6$, and the mean ISS was $33.2 \pm 7.5$. The TT, TC, and CC genotype frequencies of $A B C B 1$ C3435T were 31 (17.03\%), 96 (52.75\%), and 55 (30.22\%), respectively. The GG, GT/ GA, and TT/AA genotype frequencies of G2677T/A were 26 (14.29\%), 87 (47.80\%), and 69 (37.91\%), respectively. 
Table 1. Demographic characteristics of the patients included.

\begin{tabular}{lcc}
\hline Variables & Patients $(\mathrm{N}=182)$ & $\%$ \\
\hline Age [years (means \pm SD)] & $34.8 \pm 11.6$ & \\
$<35$ & 103 & 56.59 \\
$\geq 35$ & 79 & 43.41 \\
Gender & 123 & 67.58 \\
Male & 59 & 32.42 \\
Female & $5.8 \pm 1.6$ & \\
Mean initial GCS score & $33.2 \pm 7.5$ & \\
Mean ISS & & 17.03 \\
ABCBI C3435T & 31 & 52.75 \\
TT & 96 & 30.22 \\
CT & 55 & 14.29 \\
CC & 26 & 47.80 \\
$A B C B 1$ G2677T/A & 87 & 37.91 \\
GG & 69 & \\
GT/GA & & \\
TT/AA & & \\
\hline
\end{tabular}

GCS = Glasgow Coma Scale; ISS = Injury Severity Score.

Based on multivariate-logistic regression analysis, we found that $A B C B 1 \mathrm{C} 3435 \mathrm{~T}$ was independently associated with GOS at 6 months after adjusting for gender, age, initial GCS score, and ISS, and patients carrying the $\mathrm{CT}+\mathrm{CC}$ genotype of $A B C B 1 \mathrm{C} 3435 \mathrm{~T}$ were more likely to have a better neurological outcome than the patients with the TT genotype (odds ratio $=2.71,95 \%$ confidence interval $=1.12-6.86)($ Table 2$)$. However, we found no significant association between the G2677T/A polymorphism and TBI patient outcome.

Table 2. Association between $A B C B 1 \mathrm{C} 3435 \mathrm{~T}$ and G2677T/A and prognosis of traumatic brain injury patients.

\begin{tabular}{|c|c|c|c|c|c|c|c|c|c|c|c|c|}
\hline \multirow[t]{2}{*}{ Variables } & \multicolumn{4}{|c|}{ C3435T } & \multirow[t]{2}{*}{ OR $(95 \% \mathrm{CI})$} & \multirow[t]{2}{*}{$P$} & \multicolumn{4}{|c|}{$\mathrm{G} 2677 \mathrm{~T} / \mathrm{A}$} & \multirow[t]{2}{*}{ OR $(95 \% \mathrm{CI})$} & \multirow[t]{2}{*}{$P$} \\
\hline & TT & $\%$ & $\mathrm{CT}+\mathrm{CC}$ & $\%$ & & & GG & $\%$ & $\mathrm{GT} / \mathrm{GA}+\mathrm{TT} / \mathrm{AA}$ & $\%$ & & \\
\hline \multicolumn{13}{|c|}{ Age (years) } \\
\hline$<35$ & 18 & 58.06 & 85 & 56.29 & 1.0 (Ref.) & - & 15 & 57.69 & 88 & 56.41 & 1.0 (Ref.) & - \\
\hline$\geq 35$ & 13 & 41.94 & 66 & 43.71 & $0.93(0.39-2.17)$ & 0.86 & 11 & 42.31 & 68 & 43.59 & $0.95(0.37-2.37)$ & 0.90 \\
\hline \multicolumn{13}{|l|}{ Gender } \\
\hline Male & 20 & 64.52 & 103 & 68.21 & 1.0 (Ref.) & - & 17 & 65.38 & 106 & 67.95 & 1.0 (Ref.) & - \\
\hline Female & 11 & 35.48 & 48 & 31.79 & $1.18(0.47-2.83)$ & $0 / 69$ & 9 & 34.62 & 50 & 32.05 & $1.12(0.41-2.89)$ & 0.90 \\
\hline \multicolumn{13}{|c|}{ Mean initial } \\
\hline \multicolumn{13}{|c|}{ GCS score } \\
\hline$<5.5$ & 14 & 45.16 & 64 & 42.38 & 1.0 (Ref.) & - & 12 & 46.15 & 66 & 42.31 & 1.0 (Ref.) & - \\
\hline$\geq 5.5$ & 17 & 54.84 & 87 & 57.62 & $0.89(0.38-2.11)$ & 0.76 & 14 & 53.85 & 90 & 57.69 & $0.86(0.34-2.17)$ & 0.71 \\
\hline \multicolumn{13}{|l|}{ Mean ISS } \\
\hline$<33$ & 14 & 45.16 & 71 & 47.02 & 1.0 (Ref.) & - & 11 & 42.31 & 74 & 47.44 & 1.0 (Ref.) & - \\
\hline$\geq 33$ & 17 & 54.84 & 80 & 52.98 & $1.08(0.46-2.55)$ & 0.85 & 15 & 57.69 & 82 & 52.56 & $1.23(0.49-3.16)$ & 0.63 \\
\hline \multicolumn{13}{|c|}{ GOS at 6 months } \\
\hline$<3$ & 10 & 32.26 & 85 & 56.29 & 1.0 (Ref.) & - & 9 & 34.62 & 86 & 55.13 & 1.0 (Ref.) & - \\
\hline$\geq 3$ & 21 & 67.74 & 66 & 43.71 & $2.71(1.12-6.86)$ & & 17 & 65.38 & 70 & 44.87 & $2.32(0.91-6.27)$ & 0.05 \\
\hline
\end{tabular}

GCS = Glasgow Coma Scale; ISS = Injury Severity Score; GOS = Glasgow Outcome Scale .

\section{DISCUSSION}

In this study, we reported that the $\mathrm{C} 3435 \mathrm{~T}$ polymorphism was associated with the outcome of TBI and that the $\mathrm{CT}+\mathrm{CC}$ genotype of $A B C B 1 \mathrm{C} 3435 \mathrm{~T}$ was associated with a better neurological outcome of TBI when compared with the TT genotype.

The C allele in $A B C B 1 \mathrm{C} 3435 \mathrm{~T}$ may structurally alter substrate interaction sites and af- 
fect protein expression levels potentially by causing a translation pause because of the introduction of a rare codon (Hoffmeyer et al., 2000; Kimchi-Sarfaty et al., 2007; Fung and Gottesman, 2009). We found that the $\mathrm{C}$ allele of $A B C B 1 \mathrm{C} 3435 \mathrm{~T}$ was likely to be associated with a favorable neurological outcome of TBI. The association between the $A B C B 1 \mathrm{C} 3435 \mathrm{~T}$ polymorphism and TBI outcome can be explained by an alteration in the pharmacologic substrate carrying capacity, altered transport of unknown endogenous substrates, or disruption of the blood-brain barrier function.

Membrane-bound transporter function can be altered by silent mutations, and changes in protein folding can influence neurologic outcome by disturbing transporter binding and transport of the substrate. Moreover, exogenous and endogenous transport may be affected in the presence of genotype polymorphisms. Previous studies have shown that the $A B C B 1$ C3435T gene polymorphism plays an important role in antiepileptic medications by decreasing ABCB1 transporter function (Siddiqui et al., 2003; Hung et al., 2007; Kwan et al., 2007; Basic et al., 2008). Kwan et al. (2007) reported that patients with drug-resistant epilepsy were more likely to have the TT genotype compared to patients with drug-responsive epilepsy, which agreed with our results. However, Siddiqui et al. (2003) reported that patients with drug-resistant epilepsy were more likely to have the CC genotype for the $A B C B 1 \mathrm{C} 3435 \mathrm{~T}$ gene compared to the TT genotype.

Several studies have investigated the association between $A B C B 1$ polymorphisms and neurological disease (Liang et al., 2013; Cousar et al., 2013; Emich-Widera et al., 2013; Seven et al., 2014). Cousar et al. (2013) reported that the $\mathrm{C}$ allele of $A B C B 1 \mathrm{C} 3435 \mathrm{~T}$ was associated with a better outcome of TBI patients compared with those carrying the $\mathrm{T}$ allele. However, Seven et al. (2014) reported that the MDR1 C3435T and G2677T/A polymorphisms were not associated with antiepileptic drug resistance in Turkish epileptic patients. These inconsistent results may have been because different ethnicities were used, differences in sample size, or by chance. Further studies are needed to determine the potential role of the $A B C B 1 \mathrm{C} 3435 \mathrm{~T}$ polymorphism in the outcome of TBI patients.

There were several limitations to our study. First, the cases were selected from one hospital and thus may not have been representative of the general population. Some selection bias may have occurred because the patients were not a random sample of TBI patients and may not represent the actual situation of these patients. Second, the relatively small number of TBI cases may have limited the statistical power of identifying differences between groups. Third, other factors may affect the clinical outcome of TBI patients besides the $A B C B 1$ gene. Therefore, further larger sample sizes should be used to investigate the association between $A B C B 1$ gene polymorphisms and the outcome of TBI patients.

In conclusion, we found that the $A B C B 1 \mathrm{C} 3435 \mathrm{~T}$ polymorphism affected the clinical outcome of TBI patients. Our results have prognostic value, and the $A B C B 1 \mathrm{C} 3435 \mathrm{~T}$ polymorphism may be used as predictive marker for the outcome of TBI patients.

\section{Conflicts of interest}

The authors declare no conflict of interest.

\section{REFERENCES}

Basic S, Hajnsek S, Bozina N, Filipcic I, et al. (2008). The influence of C3435T polymorphism of ABCB1 gene on penetration 
of phenobarbital across the blood-brain barrier in patients with generalized epilepsy. Seizure 17: 524-530.

Cotte S, von Ahsen N, Kruse N, Huber B, et al. (2009). ABC-transporter gene-polymorphisms are potential pharmacogenetic markers for mitoxantrone response in multiple sclerosis. Brain 132: 2517-2530.

Cousar JL, Conley YP, Willyerd FA, Sarnaik AA, et al. (2013). Influence of ATP-binding cassette polymorphisms on neurological outcome after traumatic brain injury. Neurocrit. Care 19: 192-198.

Davidson J, Cusimano MD and Bendena WG (2015). Post-traumatic brain injury: genetic susceptibility to outcome. Neuroscientist 21: 424-441.

Ebid AH, Ahmed MM and Mohammed SA (2007). Therapeutic drug monitoring and clinical outcomes in epileptic Egyptian patients: a gene polymorphism perspective study. Ther. Drug Monit. 29: 305-312.

Emich-Widera E, Likus W, Kazek B, Niemiec P, et al. (2013). CYP3A5*3 and C3435T MDR1 polymorphisms in prognostication of drug-resistant epilepsy in children and adolescents. Biomed. Res. Int. 2013: 526837.

Fung KL and Gottesman MM (2009). A synonymous polymorphism in a common MDR1 (ABCB1) haplotype shapes protein function. Biochim. Biophys. Acta 1794: 860-871.

Hartz AM and Bauer B (2011). ABC transporters in the CNS - an inventory. Curr. Pharm. Biotechnol. 12: 656-673.

Hoffmeyer S, Burk O, von Richter O, Arnold HP, et al. (2000). Functional polymorphisms of the human multidrugresistance gene: multiple sequence variations and correlation of one allele with P-glycoprotein expression and activity in vivo. Proc. Natl. Acad. Sci. U. S. A. 97: 3473-3478.

Hung CC, Jen Tai J, Kao PJ, Lin MS, et al. (2007). Association of polymorphisms in NR1I2 and ABCB1 genes with epilepsy treatment responses. Pharmacogenomics 8: 1151-1158.

Kim RB, Leake BF, Choo EF, Dresser GK, et al. (2001). Identification of functionally variant MDR1 alleles among European Americans and African Americans. Clin. Pharmacol. Ther. 70: 189-199.

Kimchi-Sarfaty C, Oh JM, Kim IW, Sauna ZE, et al. (2007). A "silent" polymorphism in the MDR1 gene changes substrate specificity. Science 315: 525-528.

Kwan P, Baum L, Wong V, Ng PW, et al. (2007). Association between ABCB1 C3435T polymorphism and drug-resistant epilepsy in Han Chinese. Epilepsy Behav. 11: 112-117.

Langlois JA, Rutland-Brown W and Wald MM (2006). The epidemiology and impact of traumatic brain injury: a brief overview. J. Head Trauma Rehabil. 21: 375-378.

Leslie EM, Deeley RG and Cole SP (2005). Multidrug resistance proteins: role of P-glycoprotein, MRP1, MRP2, and BCRP (ABCG2) in tissue defense. Toxicol. Appl. Pharmacol. 204: 216-237.

Liang ZY, Han YL, Zhang XL, Li Y, et al. (2013). The impact of gene polymorphism and high on-treatment platelet reactivity on clinical follow-up: outcomes in patients with acute coronary syndrome after drug-eluting stent implantation. EuroIntervention 9: 316-327.

Löscher W and Potschka H (2005). Drug resistance in brain diseases and the role of drug efflux transporters. Nat. Rev. Neurosci. 6: 591-602.

Miller JD, Becker DP, Ward JD, Sullivan HG, et al. (1977). Significance of intracranial hypertension in severe head injury. J. Neurosurg. 47: 503-516.

Padayachy LC, Figaji AA and Bullock MR (2010). Intracranial pressure monitoring for traumatic brain injury in the modern era. Childs Nerv. Syst. 26: 441-452.

Samanian S, Mahjoubi F, Mahjoubi B, Mirzaee R, et al. (2011). MDR1 gene polymorphisms: possible association with its expression and clinicopathology characteristics in colorectal cancer patients. Asian Pac. J. Cancer Prev. 12: 3141-3145.

Seven M, Batar B, Unal S, Yesil G, et al. (2014). The drug-transporter gene MDR1 C3435T and G2677T/A polymorphisms and the risk of multidrug-resistant epilepsy in Turkish children. Mol. Biol. Rep. 41: 331-336.

Siddiqui A, Kerb R, Weale ME, Brinkmann U, et al. (2003). Association of multidrug resistance in epilepsy with a polymorphism in the drug-transporter gene ABCB1. N. Engl. J. Med. 348: 1442-1448. 